\title{
The role of geomorphic zonation in long-term changes in coral-community structure on a Caribbean fringing reef
}

\author{
Alexis Enrique Medina-Valmaseda ${ }^{\text {Corresp., } 1,2}{ }^{2}$, Rosa E. Rodríguez-Martínez ${ }^{2}$, Lorenzo Alvarez-Filip ${ }^{2}$, Eric Jordan- \\ Dahlgren $^{2}$, Paul Blanchon ${ }^{2}$ \\ 1 Posgrado en Ciencias del Mar y Limnología, Universidad Nacional Autónoma de México, Coyoacán, Ciudad de México, Mexico \\ 2 Instituto de Ciencias del Mar y Limnología, Universidad Nacional Autónoma de México, Puerto Morelos, Quintana Roo, Mexico \\ Corresponding Author: Alexis Enrique Medina-Valmaseda \\ Email address: alexismedina67@gmail.com
}

Ecological processes on coral reefs commonly have limited spatial and temporal scales and may not be recorded in their long-term geological history. The widespread degradation of Caribbean coral reefs over the last 40 years therefore provides an opportunity to assess the impact of more significant ecological changes on the geological and geomorphic structure of reefs. Here, we document the changing ecology of communities in a coral reef seascape within the context of its geomorphic zonation. By comparing basic ecological indices between historical and modern data we show that in 35 years the reef-front zone was transformed from a complex coral assemblage with a three-dimensional structure, to a size-homogenized and flattened one that is quasi indistinguishable from the adjacent non-accretional coral-ground zone. Today coral assemblages at Punta Maroma are characterized by the dominance of opportunistic species which are either tolerant to adverse environmental conditions, including sedimentation, or are known to be the first scleractinian species to recruit on disturbed reefs, implying they reflect a post-hurricane stage of adjustment. Despite an increase in similarity in ecological indices, the reef-front and coral-ground geomorphic zones still retain significant differences in coral assemblages and benthic habitat and are not homogeneous. The partial convergence of coral assemblages certainly has important consequences for the ecology and geological viability of the reef and its role in coastal protection, but environmental physical drivers continue to exert a fundamental role in the character and zonation of benthic communities of this reef seascape. 


\title{
The role of geomorphic zonation in long-term changes in coral-community structure on a Caribbean fringing reef
}

\author{
${ }_{4}$ Medina-Valmaseda, A.E ${ }^{1,2}$, Rodríguez-Martínez R.E. ${ }^{2}$, Álvarez-Filip L. ${ }^{2}$, \\ Jordán-Dahlgren $\mathrm{E}^{2}$, and Blanchon, P. $^{2}$

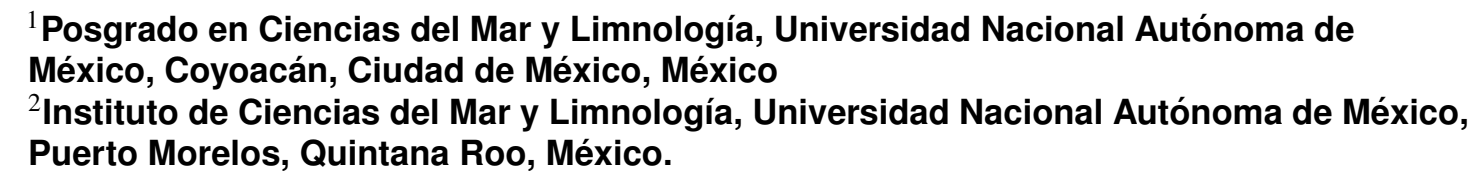

Corresponding author:

Medina-Valmaseda, A.E. ${ }^{1,2}$

Email address: alexismedina67@gmail.com

\begin{abstract}
Ecological processes on coral reefs commonly have limited spatial and temporal scales and may not be recorded in their long-term geological history. The widespread degradation of Caribbean coral reefs over the last 40 years therefore provides an opportunity to assess the impact of more significant ecological changes on the geological and geomorphic structure of reefs. Here, we document the changing ecology of communities in a coral reef seascape within the context of its geomorphic zonation. By comparing basic ecological indices between historical and modern data we show that in 35 years the reef-front zone was transformed from a complex coral assemblage with a three-dimensional structure, to a size-homogenized and flattened one that is quasi indistinguishable from the adjacent non-accretional coral-ground zone. Today coral assemblages at Punta Maroma are characterized by the dominance of opportunistic species which are either tolerant to adverse environmental conditions, including sedimentation, or are known to be the first scleractinian species to recruit on disturbed reefs, implying they reflect a post-hurricane stage of adjustment. Despite an increase in similarity in ecological indices, the reef-front and coral-ground geomorphic zones still retain significant differences in coral assemblages and benthic habitat and are not homogeneous. The partial convergence of coral assemblages certainly has important consequences for the ecology and geological viability of the reef and its role in coastal protection, but environmental physical drivers continue to exert a fundamental role in the character and zonation of benthic communities of this reef seascape.
\end{abstract}

\section{INTRODUCTION}

Coral reefs develop over geologic timescales through a complex process termed accretion (Perry and Hepburn, 2008; Pandolfi et al., 2011). Most consider this to involve a dynamic interplay between three ecological and sedimentological processes: framework growth, physical and biological erosion and internal sedimentation and cementation (Rasser and Riegl, 2002; Perry and Hepburn, 2008). Framework growth is accomplished primarily by scleractinian corals but with important contributions from calcifying encrusters, such as crustose coralline algae (Adey, 1975; Kikuchi and Leão, 1997). This growth is 
balanced by biological, chemical and physical erosion and mediated by environmental gradients in wave-energy, light penetration, and sediment flux (Geister, 1977; Huston, 1985), and produces a layer of geomorphically zoned framework (Geister, 1977; Graus and Macintyre, 1989; Kennedy and Woodroffe, 2002). Left undisturbed by storms and hurricanes, this framework has the potential to accrete vertically, as one coralgal cohort develops over another through time producing a geological reef deposit (Geister, 1980; Done, 2011).

Vertical reef accretion is clearly dependent upon short-term ecological processes persisting over thousands of years and generating a positive balance of growth and accumulation over erosion and removal. And even in zones with a positive balance, that accretion should vary significantly depending on the size and growth rate of corals in assemblages dominating each zone. For example, analysis of cores drilled on Caribbean reefs protected from hurricanes has shown that frameworks dominated by branching Acroporid corals have undergone significant vertical accretion and produced large geological reef structures during the Holocene (Macintyre and Glynn, 1976). However, in more hurricane-prone areas, cores obtained from the same zones have shown that Holocene reef structures are biodetrital consisting mostly of the fragmented remains of corals that once covered their surfaces (Blanchon et al., 1997, 2017). Furthermore, non-accretionary coral-grounds, have been reported from the extensive shelf zones both adjacent to and between the accretionary reef structures (Rodríguez-Martínez et al., 2011). Clearly the ecological seascape of reefs is complex and transient and surface coral assemblages may not always indicate how accretion occurs or even if it occurs at all.

With the demise and deterioration of Caribbean reefs during the last 40 years, and the decimation of keystone Acroporids in particular (Gardner et al., 2005; Jackson et al., 2014), this complex ecological seascape is radically changing (Perry and Alvarez-Filip, 2019). Biodiversity loss and biotic homogenization are not only compromising the ecological functioning of reefs (Olden and Poff, 2003; Burman et al., 2012; Alvarez-Filip et al., 2013; Elliff and Silva, 2017) and their ability to provide local and regional services (Alvarez-Filip et al., 2009, 2011), but are predicted to reduce their potential for long-term accretion (Perry et al., 2013; Estrada-Saldívar et al., 2019). Assessing the accuracy and validity of these accretion predictions, however, is problematic for several reasons (Lange et al., 2020). First, biotic homogenization stemming from the loss of large reef-builders, like Acroporids, makes it difficult to locate geomorphic boundaries between accretionary fringing-reef zones and adjacent non-accretionary coral-ground zones that veneer the surrounding shelf. Combining such geomorphic zones would therefore give less representative accretion potentials for reef systems. Second, use of ecological 'snapshots' to estimate the accretion potential of entire reefs makes two questionable assumptions: that drivers which exist outside of ecological timescales are unimportant in the accretion process, and that accretion is uniform in space and time (Perry, 2011; Courtney et al., 2016; Manzello et al., 2018). In terms of drivers, we know that hurricanes have played an important role in Caribbean reef accretion during the Holocene (Blanchon et al., 2017). However, little is known about changes in accretion rates, although it seems unlikely that they would remain constant given that sea level and climate has varied during the Holocene (Blanchon and Shaw, 1995; Gischler, 2006; Toscano and Macintyre, 2006; Khan et al., 2017).

In this study, we assess if homogenization has occurred between two most adjacent windward geomorphic zones along a reef at Punta Maroma, Mexico, where the long-term history of accretion is known from drilling (Blanchon et al., 2017). These geological records show the geomorphic zones have different accretion histories, and yet ecological studies commonly group them into a general 'fore-reef' zone. Although our analysis of historical vs recent ecological surveys from these zones indicates that there has been some homogenization in the abundance, species composition, and size structure of coral assemblages in adjacent geomorphic zones, we find that coral communities continue to be statistically different. 


\section{METHODS}

\section{Study site}

The study site is a $4.5 \mathrm{~km}$-long fringing reef at Punta Maroma, in the northeastern Yucatan Peninsula, close to Playa del Carmen, Quintana Roo, Mexico (Fig. 1A). It has a typical tripartite geomorphic zonation, with a reef-front, crest, and back-reef, and is flanked by a shallow $(<6 \mathrm{~m})$ lagoon on its landward side, and a deeper $(>8 \mathrm{~m}$ ) coral-veneered rock terrace, on its seaward side (Fig.1B). The geological structure of the reef front was reported by Blanchon et al. (2017) who showed that it consists of clast-dominated hurricane deposits, with a maximum age of $5.5 \mathrm{ka}$. Cores from this study also showed that the seaward coral-veneered rock terrace is a late Pleistocene extension of the coastal bedrock with no evidence of reef accretion during the Holocene.
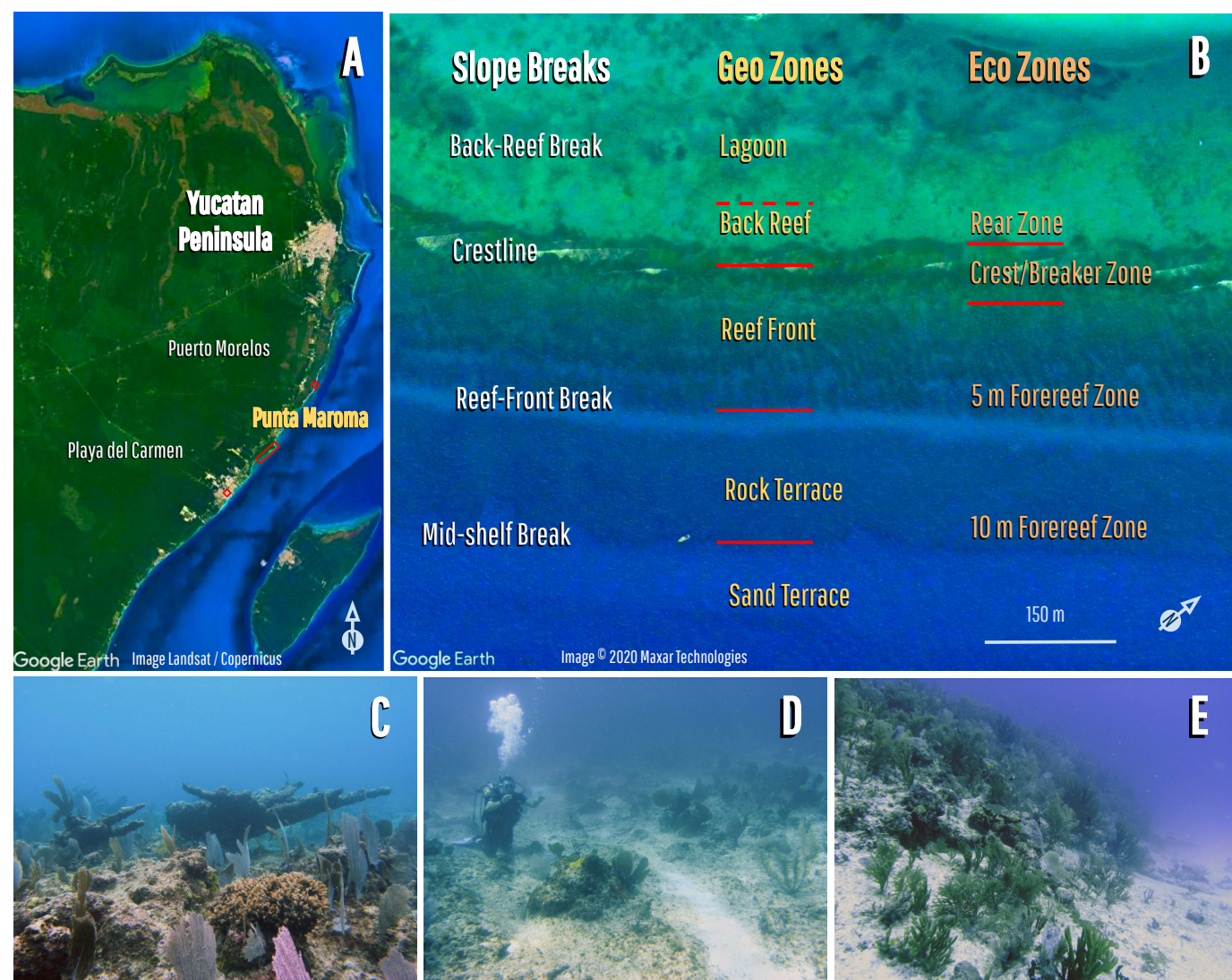

Reef-Front Break

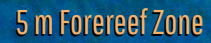

Rock Terrace
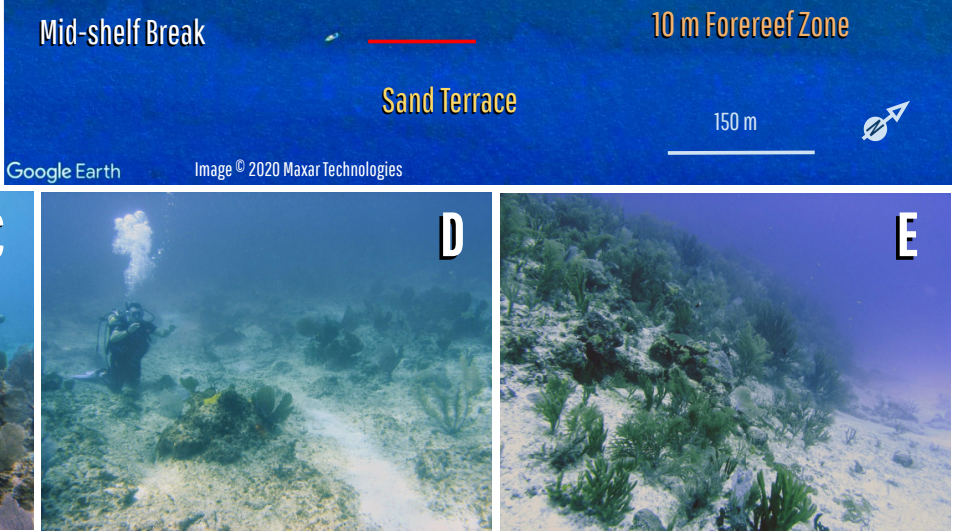

Figure 1. Ecological seascape and zonation of the fringing reef at Punta Maroma. (A) Location of Punta Maroma; (B) Reef zonation and geomorphology showing: slope breaks and geomorphological zones (following Blanchon et al., 2017) and ecological seascape zones (following Jordán-Dahlgren et al., 1981 and Estrada-Saldívar et al., 2019); (C) View of the Reef-Front zone (or Fore reef) at $~ 5 \mathrm{~m}$; (D) View of the Rock-Terrace zone (or Fore reef) at $\sim 10 \mathrm{~m}$; (E) View of the Mid-shelf break (or Fore reef) between 10 to $15 \mathrm{~m}$.

The combination of these geomorphic zones produces an extensive windward ecological seascape $\left(>2000 \mathrm{~m}^{2}\right.$ ), which consists of a shallow accretionary reef-front zone (RF), from the crest down to $\sim 6$ meters depth (Fig. 1C), and a non-accretionary deeper coral-ground (CG) zone (Fig. 1D), extending from the limit of the RF out across the rock-terrace to a mid-shelf slope break (Fig. 1E) at $\sim 10 \mathrm{~m}$ depth (Rodríguez-Martínez et al., 2011; Blanchon et al., 2017). These zones have been collectively referred to as the 'fore-reef' in other studies (Fig. 1B). 


\section{Survey methodology and Historical analysis}

To compare recent coral assemblages from the RF and CG zones at Punta Maroma reef, we surveyed coral species abundance and size between March and June, 2019. The sampling effort consisted of ten 30 m-long belt transects (BT), randomly placed in an orientation roughly parallel to the crestline at $\sim 5$ $\mathrm{m}(\mathrm{RF})$ and $\sim 10 \mathrm{~m}(\mathrm{CG})$. Sample size was determined based on historical cumulative species diversity curves, empirically determined in previous studies (Jordan et al., 1981; Jordán-Dahlgren, 1989). All scleractinian colonies with size $\geq 4 \mathrm{~cm}$ within one-metre-wide belt transects were sampled, including those intercepted by the belt line, following Zvuloni et al. (2008). Other environmental data, including depth, spatial position and distance to the mid-shelf edge, were also recorded. Scleractinian coral species were classified based on their morphology and life history following Estrada-Saldívar et al. (2019).

To determine if coral assemblages from the RF and CG zones at Punta Maroma reef experienced changes in the last few decades, we used ecological surveys taken in 1979 (Jordan et al., 1981) and in 1985 (Jordán-Dahlgren, 1989). These data were obtained from 20-m long line-intercept transects (LIT), separated from each other by distances of 5-25 m. In these studies, the transects were delimited by plastic chains (with $2.73 \mathrm{~cm}$ chain links) that followed the bottom topography. Transects were taken from three zones, described as 'rear-reef', 'breaker zone' and 'fore-reef'. In both surveys the 'fore-reef' transects were placed perpendicular to the coast at two depths: 5 and $10 \mathrm{~m}$. These three zones correspond to four geomorphological zones described by Blanchon et al. (2017): the Back Reef ('rear reef'), Reef Crest ('breaker zone'), Reef Front ('forereef' at $5 \mathrm{~m}$ ) and Rock Terrace and Mid-shelf break ('forereef' at 10 m). In this study we refer to the 'forereef' at $10 \mathrm{~m}$ as the coral-ground. All scleractinian corals below the chain were counted and measured using the chain link as the measurement unit. In 1979, the number of transects per depth was five and in 1985 four. Additionally, in 1985 colonies were measured by their maximum diameter. Every survey fulfilled the minimal sampling effort necessary to accurately describe the coral communities according to cumulative species diversity curves (Gleason, 1922). Also, because in the 1979 and 1985 Montastrea annularis, Montastraea faveolata and M. franksi were considered as part of the same species complex (M. annularis), for our 2019 surveys we combined these three species in one (Orbicella [formerly Montastrea]"annularis" complex).

\section{Approach to accretion processes}

Scleractinian corals are considered to be the principal builders of three-dimensional structures of tropical coral reefs (Goreau, 1959). However, differences in skeleton stability, size and habitat distribution of coral species, can lead to differences in their preservation potential in the geological record (Greenstein, 2007). Therefore, we use a two-level classification of the role of coral species in the accretion process to reflect the presence or species contribution the geological records. Levels were: a) key reef-building species ( key spp.), consisting of large branching Acroporids and massive Orbicella [formerly Montastrea]"annularis" complex (Budd et al., 2012), which are considered to be the principal reef builders in the Caribbean (Goreau, 1959; Lewis, 1984; Toth et al., 2019) and b) less influential species like small massive, submassive or encrusting, digitate and foliose morphologies with lower growth rates, which participate in the accretion processes but are less represented in the geological records. This group includes some abundant species in the contemporary coral communities like Agaricia agaricites and Porites astreoides (Aronson, 2006; González-Barrios and Álvarez Filip, 2018; Toth et al., 2019).

In addition to classifying their role in accretion, we also use a species Importance Value Index (IVI) (Curtis and McIntosh, 1951; Finol Urdaneta, 1971) as a proxy to estimate the relative importance of each species in the accretion processes within each geomorphic zone. For this estimation in the pre-1990's period, we used only 1985 dataset since information of 1979 data was incomplete. The IVI of each species is calculated as $I V I=(R A+R S D+R F) / 3$, where RA is relative abundance, calculated from the number of individuals per species with respect to the number of individuals of all species found in the community; where RSD is relative spatial dominance defined as the area covered by each species (using the colonies maximum and minimum diameters and assuming a planar area for the 2019 data) with respect to the cover of all species; and where RF is relative frequency, estimated as the proportion of transects where a species is present, normalised to the frequency of all species in the community. The analysis of IVI was 
carried out because different geomorphic zones within a reef have a heterogeneous accretion capacity as a consequence of the composition of the coral community and external environmental gradients (Geister, 1977; Perry, 1999).

\section{Method biases and uncertainties}

Different benthic sampling protocols and probabilistic designs tend to produce somewhat different results, and therefore different measures and indices with their own particular bias (Vallès et al. (2019) and others). However, if methodological bias is small relative to the real signal of change, then the latter should be detectable. Benthic survey methods are characterized by different spatial grain sizes of sampling units, and therefore the resulting abundance measurements could be described by different sampling distributions. However, Nadon and Stirling (2006) and Jokiel et al. (2015) reported that the method-biases associated to the results from different benthic protocols, (including the two used to collect the data we analyze here), are small relative to the true signal of changes. By contrast, Vallès et al. (2019) recently claimed that switching between benthic methods and pooling data without accounting for method differences could obscure real tendencies, for example in coral coverage percentages. The actual impact of this important source of error in further analyses of data collected by distinct benthic methods depends on the specific question to be answered and how data are treated (Ohlhorst et al., 1988; Chiappone and Sullivan, 1991; Beenaerts and Berghe, 2005). For instance, in our study, the comparative analysis was focused mostly in spatial and temporal changes in diversity composition and the correlation between species proportions by geomorphic zones, rather than in the estimation of temporal tendencies in any particular ecological index (e.g, coral cover). Yet, transect methods yield roughly the same estimates for coral genus diversity but tend to overestimate coral densities and coral coverage (Ohlhorst et al., 1988; Beenaerts and Berghe, 2005). Therefore, we consider our analysis to be more affected by an incomplete representation of the community composition rather than another method bias. We tackle the uncertainty related to the accurate representation of coral species within each geomorphic zone reaching the asymptotic zone of species accumulation curves in each zone. Ultimately, we are aware that ecological data, including abundance data, usually violate the assumptions of traditional parametric statistics, which makes it difficult to deal with using traditional univariate methods (Fieberg et al., 2020).

\section{Data transformation and Statistical analyses}

To tackle the challenge of statistical analysis of empirical ecological data, we selected a methodological approach based on multivariate analysis of abundance data. Although having some limitations, a multivariate approach has been recognized as more effective in dealing with ecological data (Beals, 1984; Fieberg et al., 2020). The approach includes several standard transformations of data, so the raw data were not compared. First, the absolute abundance data from the 2019 survey were transformed to relative spatial living coverage estimated from average colony maximum diameter and the number of individuals. This was then standardized by its total to reduce the differences in magnitude generated by the benthic method. Although the abundance data from 1979 and 1985 were relative measurements (percentage of live coral coverage), we standardized values again by its total to reduce method-bias related to the effect of the former benthic scheme that included other benthic classes (Vallès et al., 2019). In addition, data were square-root transformed to reduce the differential between the largest and smallest non-zero value in the transformed matrix. The relativization process (percentage of the total sample) was followed by an ordination process where we constructing the correspondent Bray-Curtis matrix of similarities. Additionally, each data set was transformed into Presence/Absence data and generate correspondent Jaccard matrix. Each specific multivariate test demands its additional pre-treatment procedure for the best performance. All subsequent multivariate statistical analyses were performed using Plymouth Routines in Multivariate Ecological Research (Primer-e version 7.0.13, serial number 4901, (Clarke and Gorley, 2015). Graphical outputs were constructed using the free software platform of R Core Team (2013) and Primer-e v7.0.13.

To determine the contribution of species to coral assemblages in each zone through time, we conducted a two-way similarity percentage analysis (SIMPER) for zones by time period, based on Bray-Curtis 
similarity measures of transformed square-root matrix of abundance data, making a 70\% cut-off for low contributions (Clarke and Warwick, 1994; Clarke et al., 2014). To evaluate changes in diversity we conducted a PERMANOVA and PERMDISP tests on the basis of a Jaccard transformed data matrix using previously transformed to Presence/Absence data. PERMDISP test on the basis of Jaccard matrix has been reported as a reliable test to identify changes in beta- diversity (Anderson, 2006; Anderson et al., 2006). Shade plots were created to visualize the relative contribution of all surveyed coral species to the assemblages of each geomorphic zone before the 1990s and in 2019.

To compare coral assemblages between geomorphic zones we performed two pairwise PERMANOVA tests for zones by time period, based on Bray-Curtis similarity measures of transformed square-root matrix of abundance data and in Jaccard matrix of presence-absence. To evaluate changes in coral communities of the two zones through time, we performed a two-way crossed permutational analysis (PERMANOVA) of the Bray-Curtis matrix under an orthogonal design of two fixed factors: time, with three levels (1979, 1985 and 2019), and zone, with two levels (RF and CG). Additionally, for the factor year, we designated two linear contrasts: C1 (1979 vs 1985) and C2 (1979 and 1985 vs 2019). Linear contrast is a statistical procedure that allows comparing different sub-sets of data, whereas other sub-sets can be excluded from the comparison. Search for the possibility of pooling the data subsets from 1979 and 1985 stemmed from the previous knowledge that the 1990's decade is considered a turnover moment for coral reefs worldwide, including Punta Maroma reef (Odériz et al., 2014).Therefore, we expected no differences between those data whereas the pooling process leads to a balanced design in further analysis of periods of interest. The test was done using permutation of residuals under a reduced model and Type III (partial Square Sums) in 9999 permutations (Anderson, 2001; Anderson and Braak, 2003; Anderson, 2017). To measure and test the homogeneity of multivariate dispersions of data, we performed a non-parametric permutational analysis of multivariate dispersions (PERMDISP), along with pairwise comparisons of Bray-Curtis matrix of similarities. PERMDISP was performed on the basis of distances to centroids, with P-values obtained using permutations (P(perm)) and 9999 permutations, giving the best overall results expected in terms of type I error and power (Anderson, 2006). The results are presented in a Principal coordinates analysis (PCO; (Torgerson, 1958; Gower, 1966)) constructed by calculating the distances between samples in a transformed Bray-Curtis similarity merged matrix of previously standardized and square-root transformed relative abundances matrices, for both periods in time. Pearson correlation coefficients of selected taxa were superimposed over the PCO as vectors to indicate the taxa that most strongly contributed to reef community variation. The taxa selected were derived from a similarity percentage breakdown (SIMPER) analysis of the characteristic and distinguishing reef taxa.

\section{RESULTS}

\section{Contemporary Assemblages}

In 2019, we identified and measured 724 coral colonies in the RF zone and 732 colonies in the CG zone, resulting in coral densities of $2.41 \pm 0.89$ and $2.44 \pm 0.95 \mathrm{col} . \mathrm{m}^{-2}$ respectively (Figure 2.A,B). In the RF zone, coral colonies belong to 23 species of 13 genera, and five species account for $89.4 \%$ of the colonies in the sample: Porites astreoides (55.7\%), Agaricia agaricites (11.9\%), Siderastrea siderea $(9.4 \%)$, Agaricia tenuifolia (6.9\%), and Porites porites (5.5\%); the other 18 species represent the remaining $10.6 \%$ of the sample, with none representing over 5\% (Table 1). In the CG zone, coral colonies belong to 23 species of 16 genera, and five species account for $81.5 \%$ of the sample: A. agaricites (32.5\%), $P$. astreoides (15.8\%), Montastraea cavernosa (10.2\%), S. siderea (16.4\%), and P. porites (6.4\%). The coral species that are considered to contribute most to reef accretion (Acroporids and some massive forms) represent $35 \%$ of colonies in the non-accretionary CG zone, whereas they represent only $12.8 \%$ in the RF zone with the species Acropora palmata represented by a minimal number of individuals. In both zones combined, these 'key' reef builders represent $23.9 \%$ of all colonies.

Coral colony sizes in both the RF and CG zones are predominantly small, independent of their morphology (mean $=17.9 \pm 14.7 \mathrm{~cm}$ in the RF and $19.3 \pm 15.4 \mathrm{~cm}$ in the CG (Data S1.A,S1.B), with only $2.5 \%$ of them having diameters larger than $50 \mathrm{~cm}$ in both zones. Additionally, coral colonies of all 
morphologies have low heights in both zones (mean $=6.5 \pm 8.0 \mathrm{~cm}$ in the $\mathrm{RF}$ and $10.8 \pm 11.1 \mathrm{~cm}$ in the CG). Corals with massive and sub-massive encrusting morphologies dominate both zones contributing $83.8 \%$ of the colonies in the RF and $87.8 \%$ in the CG (Fig.2A), but the identity of the dominant species differs, with the small massive $P$. astreoides dominating in the RF zone and the sub-massive encruster $A$. agaricites in the CG zone. The SIMPER test shows the groups of species that co-occur between transects (Data S2), and indicates that four species have a high degree of overlap within the CG zone: A. agaricites, S. siderea, P. astreoides, and M. cavernosa (Average similarity: 70.7), whereas in the RF zone three species overlap: P. astreoides, A. agaricites and S. siderea (Average similarity: 58.4).

\section{Historical Assemblages}

Historically, all coral morphologies had higher coral coverage in the RF zone than in the CG zone; the RF zone showed a dominance of branching morphologies and the CG zone a dominance of massive ones (Table 1; Fig. 2 C,D). The SIMPER test for historical data shows three species overlapped in the RF zone: Ac. palmata, Acropora cervicornis, and Ag. tenuifolia (Average similarity: 52.8) and five in the CG zone: M. cavernosa, Dichocoenia stokesii, S. siderea, Ag. agaricites, and Orbicella complex, (Average similarity: 42.6) (Data S1). In the RF zone, Ag. tenuifolia and Ac. palmata accounted for the largest live coral coverage (30.0\% and $23.3 \%$ respectively), and in the CG zone the dominant species were Orbicella species and M.cavernosa (12.6\% and 9.2\% respectively, Table 1). In 1985, the average diameter maximum of coral colonies (mean $=42.1 \pm 24.4 \mathrm{~cm}$ ) was more than double of those in 2019 (mean $=18.6 \pm 3.2 \mathrm{~cm}$, Data S1.A).

According to the Importance Value Index, the main species in the RF zone in 1985 were $P$. astreoides, Ag. tenuifolia and Ac. palmata and in 2019 they were P. astreoides, Acropora prolifera and Ac. palmata. The main species in the CG zone in 1985 were Orbicella species, M. cavernosa, P. astreoides and Pseudodiploria clivosa, and in 2019 they were Ag. agaricites, Colphophilia natans and S. siderea. So in $\mathrm{RF}$ zone, the relative importance of Ac. palmata and P. astreoides increased in time whereas that of $A g$. tenuifolia decreased, and in CG zone the dominant species were replaced (Fig. 3, Data S3).

\section{Comparative analysis of Coral Communities.}

Coral assemblage of the CG zone underwent significant changes in beta diversity (PERMDISP, Jaccard matrix, Fc: 4.59, $\mathrm{P}($ perm) $<0.01$; Table 2; Data S4.A), as shown in the shade plot (Fig. 4). Changes in the coral community composition of the two zones and heterogeneity in species distribution were analyzed using a two-way crossed (orthogonal) PERMANOVA. This shows strong balanced effect of zone- and time-factors over coral assemblages $(\mathrm{P}<0.001$ for each test; Estimates of components of variations: 1155.5 and 1105.5 respectively; Data $S 4 . B$ ). The test indicates a statistically significant interaction in the effects of zone and time $(\mathrm{P}<0.001)$, although the combined effect was lower (Estimates of components of variations: 390.9). Linear contrasts indicate that the effect of time was relevant when comparing 2019 vs before 1990s although there was an effect of zonation. A posteriori PERMANOVA pairwise test for both zone- and time-factors versus the zone factor, shows that the average similarity between FR and CG groups is 52.6 (Table 2; Data S4.B).

These differences in abundance and composition of coral assemblages for the two zones through time are mirrored in a Principal Coordinates Analysis (PCO) ordination procedures (Fig. 5,Data S5), which shows that A. agaricites, S. siderea, M. cavernosa, and P. astreoides have a strong negative relationship with the PCO1 axis (indicative of 2019 sites), while Ag. agaricites, S. siderea and Ac. cervicornis are neutrally related to the PCO2 axis. However, the main reef builders (acroporids and orbicellids) are strongly and positively related to the PCO1 axis (indicative of the period before 1990s), with A. palmata being positively related to RF zone before 1990s, whereas species of M. annularis spp. complex are related to CG zone (Fig. 5). Other species, such as M. cavernosa, D. stokesii, and P. strigosa, have strong negative relationships with negative sections of both axes (indicative of the CG zone). The two main axes of PCO based on abundance data reflect $35.8 \%$ (PCO1) and $24 \%(\mathrm{PCO} 2)$ of the variability inherent in the resemblance matrix. However, in the PCO based on Presence/absence data (Data S5), less 
of the variability inherent in the resemblance matrix is reflected by the two main axes $(28.1 \%$ and $16.8 \%$ respectively.

A posteriori pairwise PERMDISP test highlights that the RF zone conserve a homogeneous dispersion in variances before 1990s and 2019 data, whereas the CG zone shows heterogeneity in variance of data ( $\mathrm{P}($ tables): 0.59 and $<0.01$ respectively; Data S4.C). Therefore, the analyses indicate changes between period before 1990s and 2019 in the composition of both zones (PERMANOVA) and in the variance of sample distribution (PERMDISP) in the CG zone.

\begin{tabular}{|c|c|c|c|c|c|c|}
\hline \multirow{2}{*}{$\begin{array}{l}\text { Accretion potential of species } \\
\text { and Colony morphology }\end{array}$} & \multirow{2}{*}{$\begin{array}{l}\text { Species } \\
\text { richness }\end{array}$} & \multicolumn{2}{|c|}{ Before 1990s } & \multirow{2}{*}{$\begin{array}{c}\text { Species } \\
\text { richness }\end{array}$} & \multicolumn{2}{|c|}{2019} \\
\hline & & RF & CG & & RF & CG \\
\hline
\end{tabular}

Key reef-building_Spp.

\begin{tabular}{|c|c|c|c|c|c|c|}
\hline 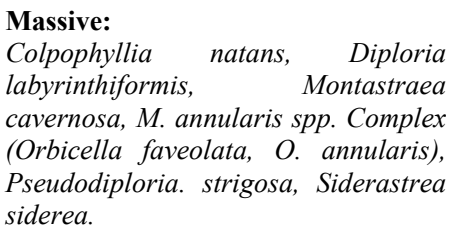 & 4 & 11 & 26 & 7 & 78 & 253 \\
\hline $\begin{array}{l}\text { Branching: } \\
\text { Acropora palmata, A. cervicornis, A. } \\
\text { prolifera }\end{array}$ & 2 & 16 & 5 & 3 & 15 & 5 \\
\hline
\end{tabular}

Non- accretional Spp.

\begin{tabular}{|c|c|c|c|c|c|c|}
\hline $\begin{array}{l}\text { Small massive: } \\
\text { Solenastrea bournoni, Isophyllia } \\
\text { rigida, Favia fragum, Dichocoenia } \\
\text { stokesii, Meandrina meandrites, } \\
\text { Porites astreoides }\end{array}$ & 9 & 10 & 26 & 6 & 408 & 136 \\
\hline $\begin{array}{l}\text { Sub-massive or encrusting: } \\
\text { Agaricia agaricites, } \quad \text { S. radians, } \\
\text { Stephanocoenia intersepta }\end{array}$ & 3 & 11 & 14 & 3 & 121 & 254 \\
\hline $\begin{array}{l}\text { Digitates: } \\
\text { Porites porites, P. furcata, } \\
\text { P. divaricata }\end{array}$ & 2 & 3 & 0 & 3 & 49 & 50 \\
\hline $\begin{array}{l}\text { Foliaceous: } \\
\text { Agaricia fragilis, A. humilis, A. } \\
\text { tenuifolia, A. lamarcki, Helioseris } \\
\text { cucullata, Mycetophyllia lamarckiana }\end{array}$ & 1 & 7 & 0 & 5 & 53 & 34 \\
\hline & 21 & 55 & 74 & 28 & 724 & 732 \\
\hline
\end{tabular}

Table 1. Coral species and number of colonies recorded in two geomorphic zones at Punta Maroma reef seascape before 1990s and in 2019. Coral species are classified according to their growth morphology (Darling et al., 2012). CG: Coral-ground zone, RF: Reef front zone of the fringing reef. Key reef-building spp.: large 'reef-building' species, Non-accretional Spp.: less influential species for accretion processes 

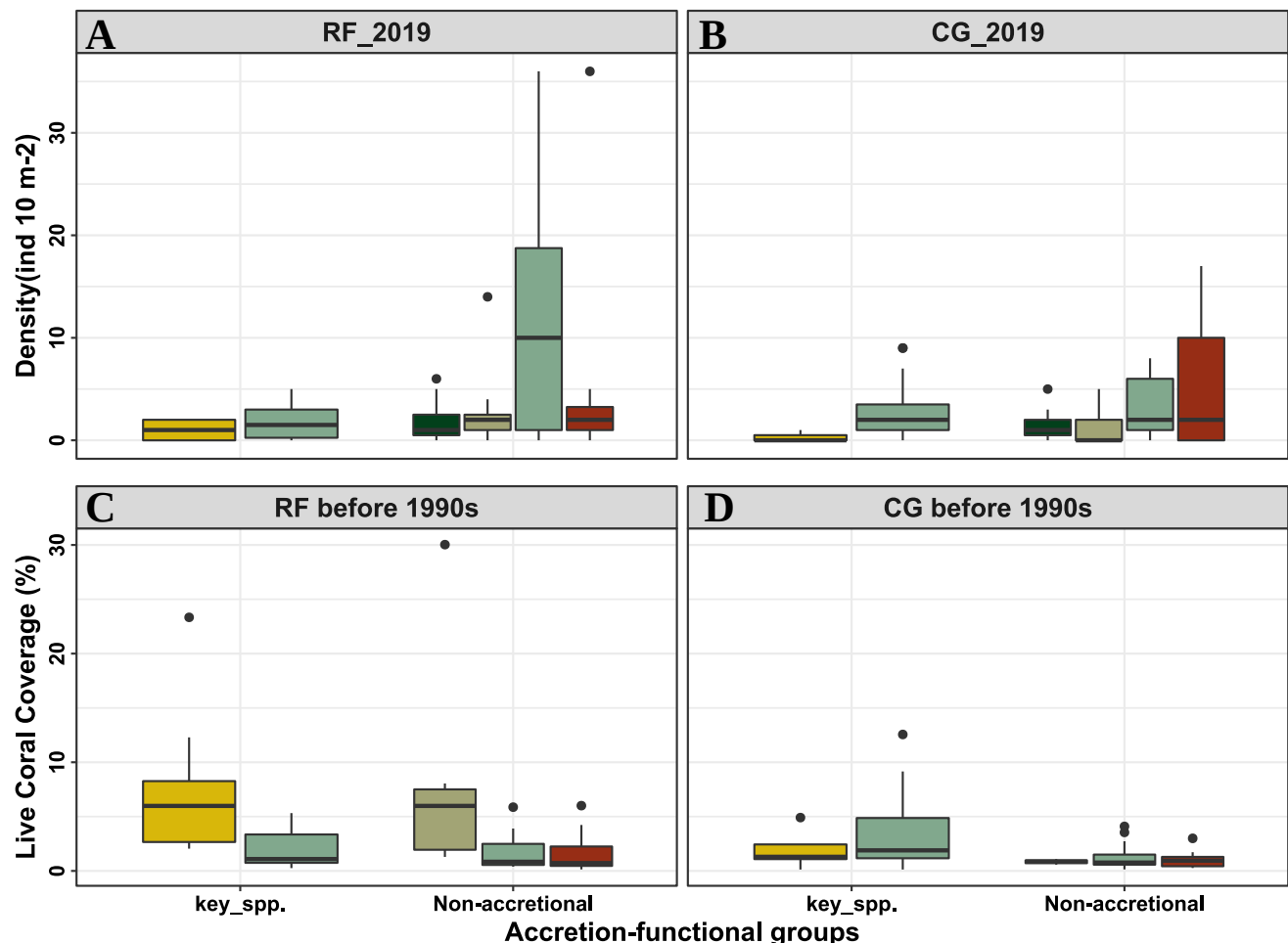

D

CG before 1990s

Colony_morphology 追 Branch

Digit 官 Foliose 官 Mass/Sm-m

Sub-mass/encr

Figure 2. Box Plots of Coral colony densities in reef-front (A) and coral-ground (B) zones in 2019. Box Plots (C) and (D) show Live coral coverage in reef front and coral-ground zones respectively before the 1990s, by accretion-functional groups, coral morphology and geomorphic zone in two reef zones at Punta Maroma reef. For the period before 1990s (panels C and D), data from 1979 and 1985 were pooled together. The bottom and top of the box are the first and third quartiles, respectively, the black line inside the box is the median. Whiskers are the lowest datum still within 1.5 times that of the lower quartile and the highest datum still within 1.5 times that of the upper quartile. RF: Reef front, or accretionary zone, CG: Coral-ground or non-accretionary zone; key_spp.: key 'reef-building' species; Non-accretional: less influential species for accretion processes. 


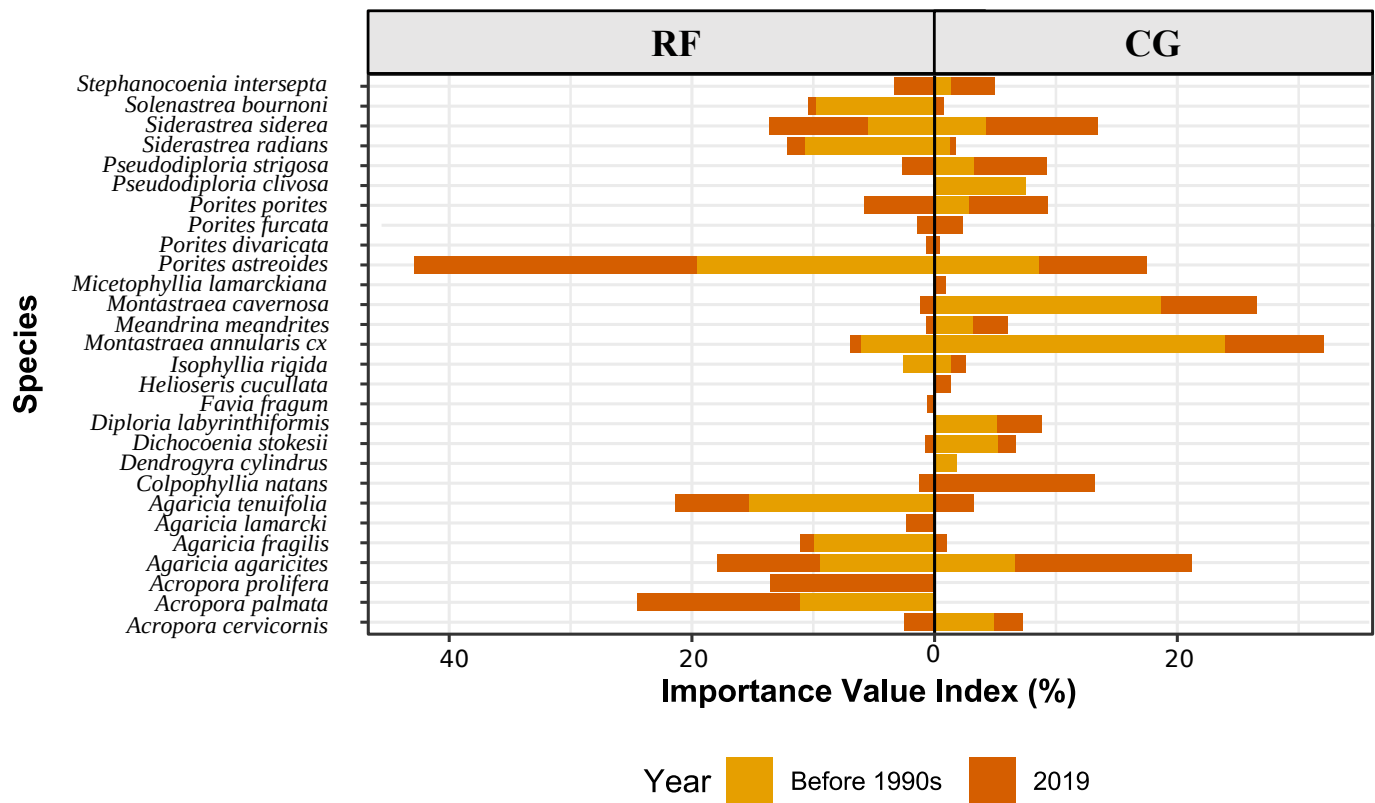

Figure 3. Ecological Importance Value Index of coral species by geomorphic zones in Punta Maroma reef before 1990s (based on 1985 data) and in 2019. The index is based on the relative abundance, frequency and spatial contribution of each species with respect to the coral assemblage.The $\mathrm{x}$ axis represent the importance value index (IVI) in percentages and the y axis list the coral species by it scientific accepted names. RF: Reef front, CG: coral-ground. 


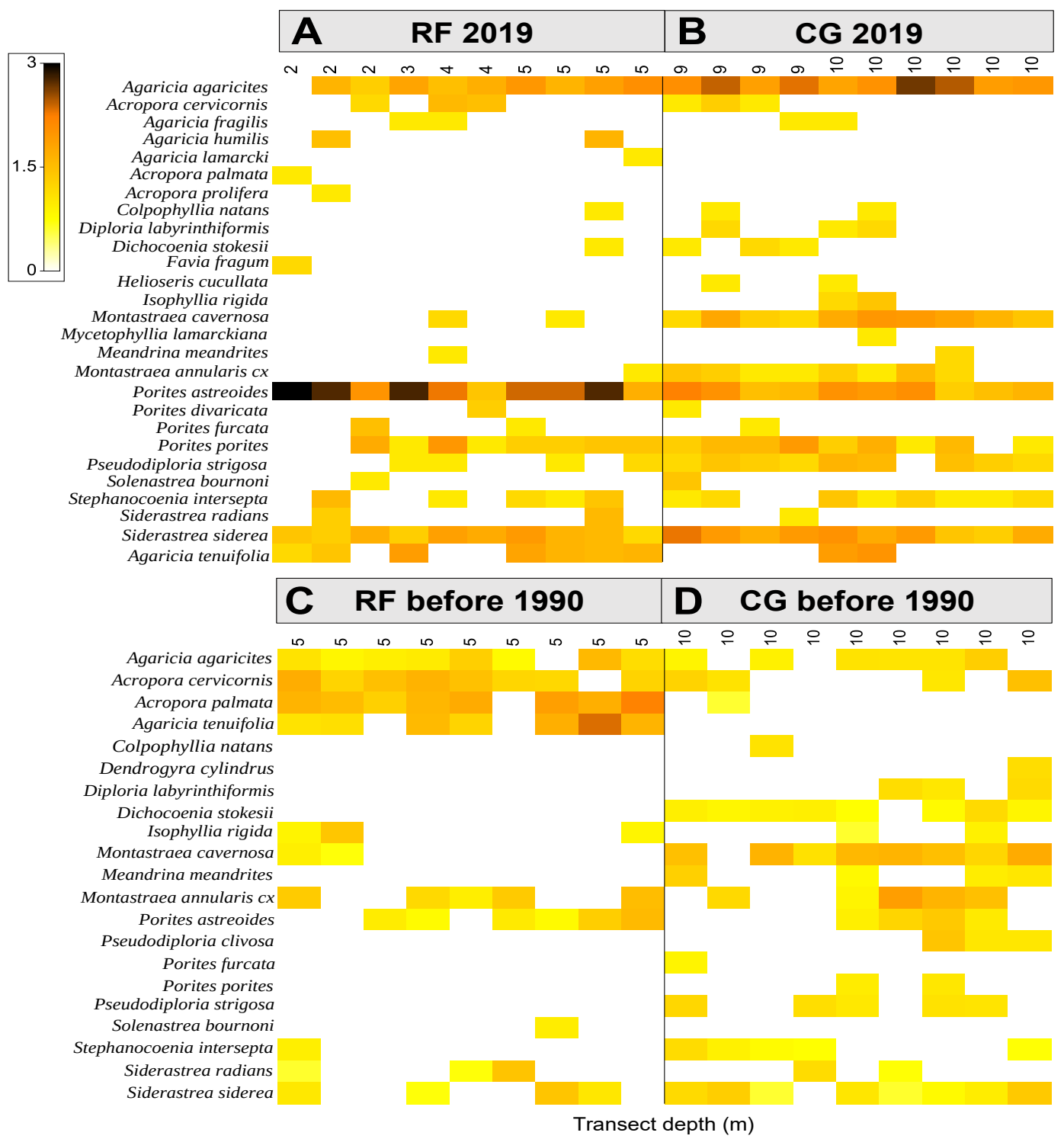

Figure 4. Comparison of the contemporary and historical abundance for each species at transect level. Color shaded plots of fourth root transformed species abundance (rows) by transect (columns) and zone (A, B: reef front RF and coral-ground,CG respectively for contemporary (2019) and C, D: reef front,RF and coral-ground,CG for historical (before 1990s) data). (A) The (ribbon) colored scale is shown in the key with back-transformed counts where white squares indicate zero counts or species accounting for $5 \%$ or less of the total abundance. The $\mathrm{x}$ axis represent the transect depth (in meters) of $\mathrm{n}$ - samples. The $\mathrm{y}$ axis represent coral species 


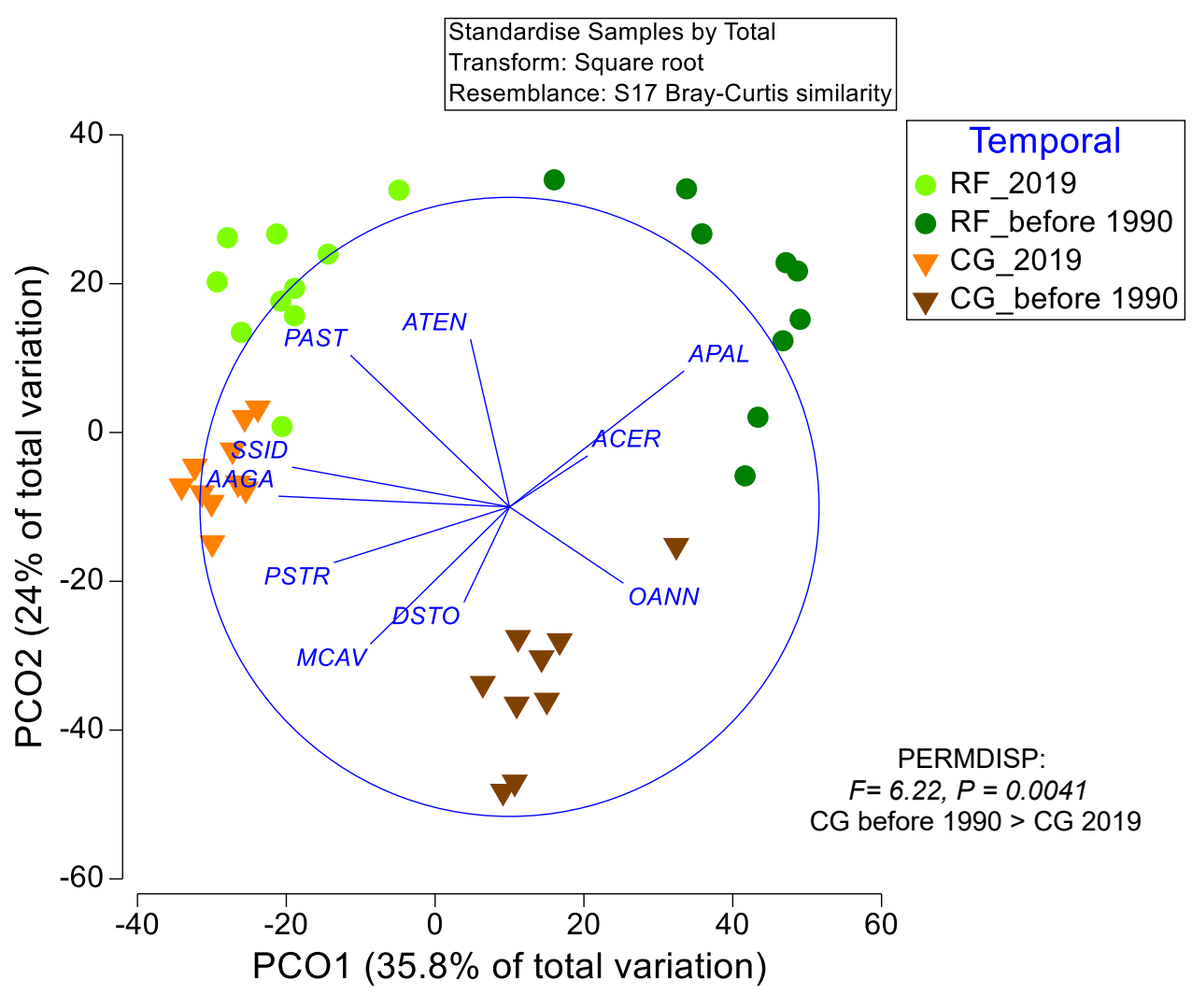

Figure 5. Principal Component Analysis (PCO) derived from the Bray-Curtis similarity matrix constructed using a fourth root transformed matrix of standardized abundances of scleractinian coral species in two sampling zones at Punta Maroma reef seascape before 1990s and in 2019: a frontal zone of a fringing reef (RF) and a coral-ground (CG) zone. Vectors visualize, through Pearson correlation coefficient, the potential monotonic relationship between the species accounting for $70 \%$ of total abundances and ordination axes a PCO. AAGA: Ag. agaricites, ATEN: Ag. tenuifolia, ACER: Ac. cervicornis, APAL: Ac. palmata, DSTO: D. stokesii, MCAV: M. cavernosa, OANN CX: Orbicella spp. complex, PAST: Po. astreoides, PSTR: Ps. strigosa, SSID: S. siderea 


\begin{tabular}{|c|c|c|c|c|c|c|c|}
\hline \multicolumn{2}{|l|}{ Raw data type } & \multicolumn{6}{|c|}{$\begin{array}{l}1979 \text { and 1985: Relative abundance (live coral coverage \%) } \\
\text { 2019: Absolute abundance (number of individuals) }\end{array}$} \\
\hline \multicolumn{2}{|l|}{ Primary transform } & \multicolumn{6}{|c|}{$\begin{array}{l}1979 \text { and 1985: Standardize by total sample } \\
\text { 2019: Standardize by total sample }\end{array}$} \\
\hline \multicolumn{2}{|l|}{ Analysis } & \multicolumn{3}{|c|}{ Abundance } & \multicolumn{3}{|l|}{ Diversity } \\
\hline \multicolumn{2}{|l|}{ Overall transform } & \multicolumn{3}{|c|}{ Square root of standardized data } & \multicolumn{3}{|c|}{ Presence-Absence } \\
\hline \multicolumn{2}{|l|}{ Resemblance } & \multicolumn{3}{|c|}{ Bray-Curtis similarities matrix } & \multicolumn{3}{|c|}{ Jaccard similarities matrix } \\
\hline two -ways PERMANOVA & & Pseudo-F & $\mathbf{p}_{(\text {perm })}$ & $\mathbf{P}(\mathbf{M C})$ & Pseudo-F & $\mathbf{p}_{(\text {perm })}$ & $\mathbf{P}(\mathbf{M C})$ \\
\hline Factor Year (3 levels: 1979, 1985, 2019 & & 13.77 & $<0.01 *$ & $<0.01 *$ & 5.45 & $<0.01$ & $<0.01$ \\
\hline C1: Contrast 1979 vs 1985 & (LIT) & 2.12 & 0.09 & 0.13 & 1.59 & 0.12 & 0.15 \\
\hline C2: Contrast (1979/1985) vs 2019 & (LIT vs BT) & 23.23 & $<0.01 *$ & $<0.01 *$ & 8.90 & $<0.01$ & $<0.01$ \\
\hline Factor Zone (2 levels: RF, CG) & & 18.27 & $<0.01$ & $<0.01$ & 11.15 & $<0.01$ & $<0.01$ \\
\hline Factor Year x Zone & & 3.16 & $<0.01$ & $<0.01$ & 1.86 & $<0.01$ & 0.02 \\
\hline C1: RF/CG 1979 vs RF/CG 1985 & (LIT) & 1.18 & 0.46 & 0.41 & 0.78 & 0.66 & 0.59 \\
\hline C2: RF/CG (79/85) vs RF/CG 2019 & (LIT vs BT) & 4.49 & $<0.01 *$ & $<0.01 *$ & 2.77 & $<0.01$ & $<0.01$ \\
\hline PERMANOVA (pair-wise tests) & & $\mathbf{t}$ & $\mathbf{p}_{(\text {perm })}$ & & $\mathbf{t}$ & $\mathbf{p}_{(\text {perm })}$ & \\
\hline RF 1979 vs CG 1979 & (LIT) & 2.95 & $<0.01$ & $<0.01$ & 2.25 & 0.07 & 0.03 \\
\hline RF 1985 vs CG 1985 & (LIT) & 2.12 & 0.03 & 0.02 & 1.97 & 0.03 & 0.02 \\
\hline RF 2019 vs CG 2019 & (LIT) & 2.93 & $<0.01$ & $<0.01$ & 2.05 & $<0.01$ & 0.01 \\
\hline \multicolumn{8}{|l|}{ PERMDISP (pair-wise tests ) } \\
\hline C2: CG (79/85) vs CG 2019 & (LIT vs BT) & 6.22 & $<0.01 *$ & & 4.59 & $<0.01$ & \\
\hline C2: RF (79/85) vs RF 2019 & (LIT vs BT) & 0.08 & 0.95 & & 0.96 & 0.39 & \\
\hline
\end{tabular}

Table 2. Results of PERMANOVA and PERMDISP tests. A synthesis of data transformation and pre-treatment procedure is presented for abundance and diversity data analyses. Bold font indicates statistically-significant differences (pairwise tests) or statistically significant interaction in the effects of factors. C1: Contrast analysis of factor year comparing 1979 vs 1985; C2: Contrast analysis of factor year comparing pooled (1979/1985) vs 2019; LIT: line intercept transect, BT: belt transect, CG: Coral-ground zone, RF: Reef front zone of the fringing reef; Some tests are highlighted with an (*) because the potential effect of data pooling in the test result (see section Method biases and uncertainties and Discussion for more information). 


\section{DISCUSSION}

Regrettably, like in other Caribbean reefs, coral assemblages covering the reefal seascape at Punta Maroma have declined markedly in the past 35 years. Prior to the 1990's, there was a clear differentiation of coral assemblages between the shallow reef front (RF) and the deeper coral-ground (CG), with the former having higher presence of Acropora spp. and Ag. tenuifolia, and the latter with higher presence of small massive species such as $M$. cavernosa, S. siderea, D. stokesii and Ag. agaricites. These coral assemblages had become more homogeneous in abundance and species composition, with similarity among zones rising from $21.49 \%$, before the 1990's, to $48.32 \%$, by 2019 (Data S4.B). Furthermore, by 2019, both the accretionary RF and the non accretionary CG community had the same coral species richness $(\mathrm{S}=$ $23)$, roughly the same colony density $\left(2.4\right.$ per $\left.\mathrm{m}^{2}\right)$ and were dominated by small colonies $(<20 \mathrm{~cm})$ of $S$. siderea, $P$. astreoides, Ag. agaricites, and P. porites. However, according to the Index Value of Importance (IVI), reef builders like Ac. palmata conserved its high ecological value in the RF zone, despite its reduction in abundance through time, and the Orbicella (formerly Montastrea) reef-building group has a high value in the CG zone through time, despite the fact that this is a non-accretionary zone.

Reductions of live coral cover and decline in the abundance of large key reef-building species have been reported from other Caribbean reefs, together with the increase in the similarity of the coral assemblages and concomitant decrease in the visual difference amongst shallow adjacent coral-reef zones (Gardner et al., 2003; Jackson et al., 2014). Although the boundaries between these reef communities have often been defined by both biological and geological characteristics, these definitions have been inconsistent (e.g., ecozones in Fig.1b). For example, Estrada-Saldívar et al. (2019) recently reported that similar ecological changes led to functional convergence and homogenization between back-reef and fore-reef sites along the north-east Yucatan, including the one at Punta Maroma. However they considered the RF and CG zones as a single 'fore-reef' zone. A similar approach was followed by Jordan et al. (1981) to describe the windward zone of the entire Mexican Caribbean. Our findings show that on a more detailed scale, however, this ecological homogenization is incomplete and that each geomorphic zone still retains differences. A good example are the PERMANOVA results of pairwise tests based on abundance data. Although these could be obscured by uncertainties related to the method bias and disparate nature of raw abundance metrics, differences are also supported by the sibling test based on presence-absence data, which is more reliable. Furthermore the homogenization of colony sizes by 2019 imply that the absolute-abundance data could be used as an estimate of coral coverage. Further indication that abundance values are involved are the lower levels of variability in the resemblance matrix illustrated by PCO axes in the presence/absence version compared to the sibling PCO axes in abundance. Thus, we show that changes in beta-biodiversity identified by biodiversity analysis are partially responsible for the main temporal differences. It may be that this 'partial' homogenization results from a convergence in species succession within each geomorphic zone, as reported on other Caribbean reefs (e.g. (Curran et al., 1995; Aronson and Precht, 1997)

As highlighted by the statistical analysis, ecological differences in species distribution and their relative importance between adjacent geomorphic zones may be related to long-term environmental processes. Despite changes in community structure, the RF zone still has an irregular substrate, with stumps of dead A. palmata and several acroporid spur-and-groove sets that slope up to the crest, and the CG zone is still a flat undulating rocky terrace crossed by shallow furrows and coral veneered ridges. These conditions favour the persistence of sediment-tolerant species, like M. cavernosa, A. agaricites (Lasker, 1980; Erftemeijer et al., 2012) and S. siderea in the CG zone, whereas in the RF zone the higher dominance of $P$. astreoides, which colonized space vacated by $A$. palmata may be a successional stage following disturbance. If this interpretation is correct then it highlights the importance of long-term adaptive responses of coral species to geomorphic substrates.

Although retaining some of their geomorphic character, these once easy to differentiate geomorphic zones are now more difficult to separate based on coral cover or other ecological indices. This difficulty stems from the functional loss of major reef builders such as Acroporids (e.g., A. palmata, A. cervicornis) which are largely responsible for long-term accretion in shallow Caribbean reefs (Macintyre and Glynn, 1976; Blanchon et al., 2017; Toth et al., 2019). These losses were likely driven by multiple strikes from 
major Hurricanes that crossed the study area (Allen in 1980, Gilbert in 1988, Emily in 2005 and Wilma in 2005), and their coincident timing with white band/pox epidemics that were decimating acroporids elsewhere (Gladfelter, 1982; Lewis, 1984; Aronson and Precht, 2001; Bruckner, 2002). Although there is debate over the proximate cause (hurricanes vs disease outbreaks) the result was the same: a partial convergence of shallow coral communities with a concomitant structural deterioration (Jackson et al., 2014; Elliff and Silva, 2017). At Punta Maroma the largest decline in Acropids had taken place by the mid-1980s, and no additional evidence of large-scale species succession has been reported since, although disturbances have not decreased (Nyström et al., 2000; Schutte et al., 2010; Graham et al., 2011; Rioja-Nieto and Álvarez-Filip, 2019). This rapid decline at Punta Maroma is likely related to a regional species succession stemming from the widespread mortality of A. palmata and A. cervicornis, and their replacement by more successful representatives of the Agariciidae and Poritidae, as reported previously Aronson and Precht (2001).

The rapid transition to a partially homogenized coral community at Punta Maroma today is inconsistent with the reef's Holocene record, implying the importance of these changes for the future accretion potential of the reef. But assessing the contribution of key reef-building species, such as A. palmata, in this accretion process based on their current ecological condition is a challenging exercise which depends on the type of ecological indicator used. Analysis of changes in species abundance and composition on a relatively short time-scale indicates a reduction in its contribution and an inferred loss in accretion potential. However, more complex measures than relative abundance, like the IVI analysis, indicates that some acroporids have retained their relative importance, highlighting the important contribution of this species to reef accretion. This is because the IVI includes other data such as colony size in addition to species abundances, and so gives a more complete picture. Nevertheless, such indices may still not provide an accurate picture of which species is important for accretion. For example, relative abundance data indicate that the CG zone now has more reef-building species, implying a higher accretion potential, despite the fact that CG zone has been repeatedly reported as non-accretional one (Rodríguez-Martínez et al., 2011; Blanchon et al., 2017). As a consequence, even the best-suited ecological indices of reef-accretion potential may not give accurate estimates unless the geomorphic context of coral communities is considered in more detail. Furthermore, although ecological studies may provide a detailed snapshot of historical timescales, they may not be fully representative of the long-term development in complex geomorphologically zoned reef structures (Aronson and Precht, 1997; Bellwood et al., 2004; Bruckner, 2012). For example, Vallès et al. (2019) recently demonstrate that each reef type has its own pattern of coral coverage and that between reef types there are differences not related to method bias. Similarly, intrinsic ecological patterns can also be identified with more detailed scrutiny of the geomorphic zonation because, as we have shown here, differences occur not just in coral coverage but in the taxonomic groups. Thus, by using geomorphic zones and other than coral coverage metrics, our results suggest the presence of within reef types (additional to those among reef types) ecological patterns.

Finally, the ecological dynamics of reef-building communities raises an interesting question about how they create geological structures over thousands of years. Ecological assessments assume that reef accretion potential is a function of the carbonate production rate of the site (gross production of primary and secondary producers less gross erosion of bioeroders (Perry and Morgan, 2017)), and therefore this balance defines the persistence of reef structure. Whereas those core processes undoubtedly lead to accretion, other processes are poorly represented, like physical erosion and transport of coral skeletons by storm swell or hurricane, and the patchiness and species zonation inherent to biological processes (Perry, 1999; Purkis and Kohler, 2008). Although it is challenging to incorporate physical erosion within the accretion potential estimates, geomorphic zonation is a more predictable factor with definable boundaries (Blanchon, 2011). Furthermore, the assumptions that reefs were always covered by dense coral thickets or inhabited the same contemporary reef areas is questionable and ignores processes that exist outside of ecological timescales, for example, changes in sea level and the related processes of retrogradation or progradation of the reef structure (Graus and Macintyre, 1989). Indeed, little is known about the patterns of long-term accretion because geological reconstructions are largely two dimensional, deriving data from single drill holes or drill transects, and therefore assume accretion is a homogeneous process in space and time. It may be, for example, that accretion is heterogeneous in space and time and that some sections of a reef develop at different intervals, in different areas through time. In this case, some ecological conditions 
may not be representative of geological trends (Jackson, 1992).

\section{CONCLUSIONS}

Over the last 40 years, coral assemblage data show that the two main windward geomorphic zones at Punta Maroma have maintained ecologic and benthic differences, implying that physical environmental drivers continue to exert a fundamental control on this reefal seascape. As a consequence, we suggest that a consideration of geomorphic zonation is a fundamental prerequisite for determining the accretion potential of entire reef systems. These results also indicate that there has been a partial homogenization of coral assemblages over that interval involving the loss of key reef-building species, which has raised concern about future accretion potential and the role of reef structures for coastal services. However, by considering the more detailed changes between geomorphic zones, our data do not rule out the possibility that accretion may in-fact be heterogeneous in space and time and that present-day coral communities may be the result of successional failure induced by chronic anthropogenic disturbance related to mass tourism along the Mayan Riviera.

\section{ACKNOWLEDGMENTS}

We are grateful with E. Perez-Cervantes and N. Estrada-Saldívar who participated in the coral surveys of 2019, and with L.M. Guzmán, A. González de la Parra and M. Sánchez who assisted in the survey of 1979 and 1985. I. Ortega, E.G. Islas Domínguez and F. Medellín assisted with data collection and logistics. Edlin Guerra Castro assisted greatly with multivariate statistical data analysis.

\section{ADDITIONAL INFORMATION AND DECLARATIONS}

Alexis E. Medina-Valmaseda conceived and designed the experiments, performed the experiments, analyzed the data, prepared figures and/or tables, helped write and review drafts of the paper, and approved the final draft.

Rosa E. Rodríguez-Martínez helped write and review drafts of the paper, and approved the final draft.

Lorenzo Álvarez-Filip performed the experiments, helped write, reviewed drafts of the paper, and approved the final draft.

Eric Jordán-Dahlgren helped write and review drafts of the paper, statistically analyzed the data, and approved the final draft.

Paul Blanchon helped design the experiment, prepared figures, helped write, review drafts of the paper and approved the final draft.

\section{REFERENCES}

Adey, W. H. (1975). The algal ridges and coral reefs of St.Croix: their structure and Holocene development. Atoll Research Bulletin. doi:10.5479/si.00775630.187.1.

Alvarez-Filip, L., Carricart-Ganivet, J. P., Horta-Puga, G., and Iglesias-Prieto, R. (2013). Shifts in coral-assemblage composition do not ensure persistence of reef functionality. Scientific reports, 3:3486. doi:10.1038/srep03486. 
Alvarez-Filip, L., Dulvy, N. K., Gill, J. A., Co^té, I. M., and Watkinson, A. R. (2009). Flattening of Caribbean coral reefs: region-wide declines in architectural complexity. Proceedings of the Royal Society B: Biological Sciences, 276(1669):3019-3025. doi:10.1098/rspb.2009.0339.

Alvarez-Filip, L., Gill, J., Dulvy, N., Perry, A., Watkinson, A., and Côté, I. (2011). Drivers of region-wide declines in architectural complexity on Caribbean reefs. Coral Reefs, 30(4):1051. doi: $10.1007 / s 00338-011-0795-6$.

Anderson, M. and Braak, C. T. (2003). Permutation tests for multi-factorial analysis of variance. Journal of statistical computation and simulation, 73(2):85-113. doi:10.1080/00949650215733.

Anderson, M. J. (2001). A new method for non-parametric multivariate analysis of variance. Austral ecology, 26(1):32-46. doi:0.1111/j.1442 - 9993.2001.01070.

Anderson, M. J. (2006). Distance-based tests for homogeneity of multivariate dispersions. Biometrics, 62(1):245-253. doi:10.1111/j.1541-0420.2005.00440.

Anderson, M. J. (2017). Permutational multivariate analysis of variance (PERMANOVA). Wiley statsref: statistics reference online, pages 1-15. doi:10.1002/9781118445112.stat07841.

Anderson, M. J., Ellingsen, K. E., and McArdle, B. H. (2006). Multivariate dispersion as a measure of beta diversity. Ecology letters, 9(6):683-693. doi:10.1111/j.1461 - 0248.2006.00926.x.

Aronson, R. B. (2006). Global change and biotic homogenization of coral reefs. In 2006 Philadelphia Annual Meeting.

Aronson, R. B. and Precht, W. F. (1997). Stasis, biological disturbance, and community structure of a Holocene coral reef. Paleobiology, 23(3):326-346. doi:10.1017/s0094837300019710.

Aronson, R. B. and Precht, W. F. (2001). White-band disease and the changing face of Caribbean coral reefs. In The ecology and etiology of newly emerging marine diseases, pages 25-38. Springer.

Beals, E. W. (1984). Bray-curtis ordination: an effective strategy for analysis of multivariate ecological data. In Advances in ecological research, volume 14, pages 1-55. Elsevier.

Beenaerts, N. and Berghe, E. V. (2005). Comparative study of three transect methods to assess coral cover, richness and diversity. Western Indian Ocean Journal of Marine Science, 4(1):29-38. doi:10.4314/wio jms.v4i1.28471.

Bellwood, D. R., Hughes, T. P., Folke, C., and Nyström, M. (2004). Confronting the coral reef crisis. Nature, 429(6994):827-833.

Blanchon, P. (2011). Geomorphic zonation. Encyclopedia of modern coral reefs, pages 469-486. doi: $10.1007 / 978-90-481-2639-2333$.

Blanchon, P., Jones, B., and Kalbfleisch, W. (1997). Anatomy of a fringing reef around Grand Cayman; storm rubble, not coral framework. Journal of Sedimentary Research, 67(1):1-16. doi: $10.1306 / d 42684 d 7-2 b 26-11 d 7-8648000102 c 1865 d$.

Blanchon, P., Richards, S., Bernal, J. P., Cerdeira-Estrada, S., Ibarra, M., Corona-Martínez, L., and Martell-Dubois, R. (2017). Retrograde accretion of a Caribbean fringing reef controlled by hurricanes and sea-level rise. Frontiers in Earth Science, 5:78. doi:10.3389/feart.2017.00078.

Blanchon, P. and Shaw, J. (1995). Reef drowning during the last deglaciation: evidence for catastrophic sea-level rise and ice-sheet collapse. Geology, 23(1):4-8. doi:10.1130/0091-7613(1995)0232.

Bruckner, A. W. (2002). Priorities for effective management of coral diseases. US Department of Commerce, National Oceanic and Atmospheric Administration.

Bruckner, A. W. (2012). Static measurements of the resilience of Caribbean coral populations. Revista de Biologia Tropical, 60:39-57. doi:10.15517/rbt.v60i0.19844.

Budd, A. F., Nunes, F. L., Weil, E., and Pandolfi, J. M. (2012). Polymorphism in a common atlantic reef coral ( Montastraea cavernosa) and its long-term evolutionary implications. Evolutionary ecology, 26(2):265-290. doi:10.15517/rbt.v60i0.19844.

Burman, S. G., Aronson, R. B., and van Woesik, R. (2012). Biotic homogenization of coral assemblages along the Florida reef tract. Marine Ecology Progress Series, 467:89-96. doi:10.3354/meps09950.

Chiappone, M. and Sullivan, K. (1991). A comparison of line transect versus linear percentage sampling for evaluating stony coral (scleractinia andmilleporina) community similarity and area coverage on reefs of the central bahamas. Coral Reefs, 10(3):139-154.

Clarke, K. and Gorley, R. (2015). Getting started with primer v7. PRIMER-E: Plymouth, Plymouth Marine Laboratory, page 20.

Clarke, K. and Warwick, R. (1994). Similarity-based testing for community pattern: the two-way layout with no replication. Marine Biology, 118(1):167-176. doi:10.1007/b f00699231. 
Clarke, K. R., Gorley, R., Somerfield, P. J., and Warwick, R. (2014). Change in marine communities: an approach to statistical analysis and interpretation. Primer-E Ltd.

Courtney, T. A., Andersson, A. J., Bates, N. R., Collins, A., Cyronak, T., de Putron, S. J., Eyre, B. D., Garley, R., Hochberg, E. J., Johnson, R., Musielewicz, S., Noyes, T. J., Sabine, C. L., Sutton, A. J., Toncin, J., and Tribollet, A. (2016). Comparing chemistry and census-based estimates of net ecosystem calcification on a rim reef in Bermuda. Frontiers in Marine Science, 3:181. doi:10.3389/fmars.2016.00181.

Curran, H., Smith, D., Meigs, L., Pufall, A., and Greer, M. (1995). The health and short-term change of two coral patch reefs, Fernandez Bay, San Salvador Island, Bahamas. Oceanographic Literature Review, 8(42):674-675.

Curtis, J. T. and McIntosh, R. P. (1951). An upland forest continuum in the prairie-forest border region of Wisconsin. Ecology, 32(3):476-496.

Done, T. (2011). Coral Reef, Definition, pages 261-267. Springer Netherlands, Dordrecht.

Elliff, C. I. and Silva, I. R. (2017). Coral reefs as the first line of defense: Shoreline protection in face of climate change. Marine environmental research, 127:148-154. doi:10.1016/ j.marenvres.2017.03.007.

Erftemeijer, P. L., Riegl, B., Hoeksema, B. W., and Todd, P. A. (2012). Environmental impacts of dredging and other sediment disturbances on corals: a review. Marine pollution bulletin, 64(9):1737-1765. doi:10.1016/j.marpolbul.2012.05.008.

Estrada-Saldívar, N., Jordán-Dalhgren, E., Rodríguez-Martínez, R. E., Perry, C., and Alvarez-Filip, L. (2019). Functional consequences of the long-term decline of reef-building corals in the Caribbean: evidence of across-reef functional convergence. Royal Society Open Science, 6(10):190298.

Fieberg, J. R., Vitense, K., and Johnson, D. H. (2020). Resampling-based methods for biologists. PeerJ, 8:e9089.

Finol Urdaneta, H. (1971). Nuevos parámetros a considerarse en el análisis estructural de las selvas vírgenes tropicales. Revista Forestal Venezolana (Venezuela) v. 14 (21) p. 29-42. doi: $10.1098 /$ rsos. 190298.

Gardner, T. A., Côté, I. M., Gill, J. A., Grant, A., and Watkinson, A. R. (2003). Long-term region-wide declines in Caribbean corals. science, 301(5635):958-960.

Gardner, T. A., Côté, I. M., Gill, J. A., Grant, A., and Watkinson, A. R. (2005). Hurricanes and Caribbean coral reefs: impacts, recovery patterns, and role in long-term decline. Ecology, 86(1):174-184. doi:10.1890/04 - 0141.

Geister, J. (1977). The influence of wave exposure on the ecological zonation of Caribbean coral reefs. In Proceedings of the 3rd International Coral Reef Symposium, 1977, volume 1, pages 23-29. doi:10.4236/ajcc.2012.11003.

Geister, J. (1980). Calm-water reefs and rough-water reefs of the Caribbean pleistocene. Acta Palaeontologica Polonica, 25(3-4).

Gischler, E. (2006). Comment on "corrected western Atlantic sea-level curve for the last 11,000 years based on calibrated $14 \mathrm{C}$ dates from Acropora palmata framework and intertidal mangrove peat" by Toscano and Macintyre. coral reefs 22: 257-270 (2003), and their response in coral reefs 24: 187-190 (2005). Coral Reefs, 25(2):273-279. doi:10.1007/s00338 - 006 - 0101 - 1.

Gladfelter, W. B. (1982). White-band disease in Acropora palmata: implications for the structure and growth of shallow reefs. Bulletin of Marine Science, 32(2):639-643. doi:10.1007/978 - 94 - 017 $3284-0$ - 2 .

Gleason, H. A. (1922). On the relation between species and area. Ecology, 3(2):158-162. doi: $10.2307 / 1929150$.

González-Barrios, F. J. and Álvarez Filip, L. (2018). A framework for measuring coral speciesspecific contribution to reef functioning in the Caribbean. Ecological Indicators, 95:877-886. doi:10.1016/ j.ecolind.2018.08.038.

Goreau, T. F. (1959). The Ecology of Jamaican Coral Reefs I. Species Composition and Zonation. Ecology, 40(1):67-90. doi:10.2307/1929924.

Gower, J. C. (1966). Some distance properties of latent root and vector methods used in multivariate analysis. Biometrika, 53(3-4):325-338. doi:10.2307/2333639.

Graham, N., Nash, K., and Kool, J. (2011). Coral reef recovery dynamics in a changing world. Coral Reefs, 30(2):283-294. doi:10.1007/s00338 - 010-0717-z.

Graus, R. R. and Macintyre, I. G. (1989). The zonation patterns of Caribbean coral reefs as controlled by wave and light energy input, bathymetric setting and reef morphology: computer simulation 
experiments. Coral reefs, 8(1):9-18. doi:10.1007/b f00304687.

Greenstein, B. J. (2007). Taphonomy: detecting critical events in fossil reef-coral assemblages. In Geological approaches to coral reef ecology, pages 31-60. Springer.

Huston, M. (1985). Patterns of species diversity on coral reefs. Annual review of ecology and systematics, 16(1):149-177. doi:10.1146/annurev.es.16.110185.

Jackson, J., Donovan, M., Cramer, K., and Lam, L. (2014). Status and Trends of Caribbean Coral Reefs1970-2012-2014 Caribbean Coral Reefs-Status Report 1970-2012 (1). Global Coral Reef Monitoring Network, IUCN Gland.

Jackson, J. B. C. (1992). Pleistocene Perspectives on Coral Reef Community Structure1. American Zoologist, 32(6):719-731. doi:10.1093/icb/32.6.719.

Jokiel, P. L., Rodgers, K. S., Brown, E. K., Kenyon, J. C., Aeby, G., Smith, W. R., and Farrell, F. (2015). Comparison of methods used to estimate coral cover in the hawaiian islands. PeerJ, 3:e954. doi: 10.7717 /peer j.954.

Jordan, E., Merino, M., Moreno, O., and Martin, E. (1981). Community structure of coral reefs in the Mexican Caribbean. In Proc 4th Int Coral Reef Symp, volume 2, pages 303-308.

Jordán-Dahlgren, E. (1989). Efecto de la morfología del sustrato en el desarrollo de la comunidad coralina. In Anales del Instituto de Ciencias del Mar y Limnología, Universidad Nacional Autónoma de México, volume 16, pages 105-118.

Kennedy, D. and Woodroffe, C. (2002). Fringing reef growth and morphology: a review. Earth-Science Reviews, 57(3-4):255-277. doi:10.1016/s0012 - 8252(01)00077-0.

Khan, N. S., Ashe, E., Horton, B. P., Dutton, A., Kopp, R. E., Brocard, G., Engelhart, S. E., Hill, D. F., Peltier, W., Vane, C. H., and Scatena, F. N. (2017). Drivers of Holocene sea-level change in the Caribbean. Quaternary Science Reviews, 155:13-36. doi:10.1016/ j.quascirev.2016.08.032.

Kikuchi, R. d. and Leão, Z. (1997). Rocas (southwestern equatorial atlantic, brazil): an atoll built primarily by coralline algae. In Proc 8th Int Coral Reef Symp, volume 1, pages 731-736.

Lange, I. D., Perry, C. T., and Alvarez-Filip, L. (2020). Carbonate budgets as indicators of functional reef "health": A critical review of data underpinning census-based methods and current knowledge gaps. Ecological Indicators, 110:105857. doi:10.1016/ j.ecolind.2019.105857.

Lasker, H. R. (1980). Sediment rejection by reef corals: the roles of behavior and morphology in Montastrea cavernosa (Linnaeus). Journal of Experimental Marine Biology and Ecology, 47(1):77-87. doi:10.1016/0022 - 0981(80)90139-2.

Lewis, J. B. (1984). The acropora inheritance: a reinterpretation of the development of fringing reefs in Barbados, West Indies. Coral Reefs, 3(3):117-122.

Macintyre, I. and Glynn, P. (1976). Evolution of modern Caribbean fringing reef,Galeta Point, Panama. AAPG Bulletin, 60(7):1054-1072. doi:10.1306/c1ea3618 - 16c9-11d7-8645000102c1865d.

Manzello, D. P., Enochs, I. C., Kolodziej, G., Carlton, R., and Valentino, L. (2018). Resilience in carbonate production despite three coral bleaching events in 5 years on an inshore patch reef in the Florida Keys. Marine Biology, 165(6):1-11.

Nadon, M.-O. and Stirling, G. (2006). Field and simulation analyses of visual methods for sampling coral cover. Coral Reefs, 25(2):177-185. doi:10.1007/s00338 - 005 - $0074-5$.

Nyström, M., Folke, C., and Moberg, F. (2000). Coral reef disturbance and resilience in a humandominated environment. Trends in Ecology \& Evolution, 15(10):413-417. doi:10.1016/s0169 $5347(00) 01948-0$.

Odériz, I., Mendoza, E., Leo, C., Santoyo, G., Silva, R., Martínez, R., Grey, E., and López, R. (2014). An alternative solution to erosion problems at punta bete-punta maroma, quintana roo, mexico: Conciliating tourism and nature. Journal of Coastal Research, 71(sp1):75-85. doi:10.2112/SI71 -009.1.

Ohlhorst, S. L., Liddell, W., Taylor, R., and Taylor, M. (1988). Evaluation of reef census techniques. In Sixth Int. Coral Reef Symp, volume 2, page 319.

Olden, J. D. and Poff, N. L. (2003). Toward a mechanistic understanding and prediction of biotic homogenization. The American Naturalist, 162(4):442-460.

Pandolfi, J. M., Connolly, S. R., Marshall, D. J., and Cohen, A. L. (2011). Projecting coral reef futures under global warming and ocean acidification. science, 333(6041):418-422. doi:10.1126/science. 1204794 .

Perry, C. (2011). Carbonate budgets and reef framework accumulation. Encyclopedia of modern coral reefs: structure, form and process. Dordrecht: Springer, pages 185-190. doi:10.1007/978 - 90 - 
$481-2639-2.53$.

Perry, C. and Morgan, K. (2017). Bleaching drives collapse in reef carbonate budgets and reef growth potential on southern Maldives reefs. Scientific reports, 7:40581. doi:10.1038/srep40581.

Perry, C. T. (1999). Reef framework preservation in four contrasting modern reef environments, Discovery Bay, Jamaica. Journal of Coastal Research, pages 796-812. doi:10.1038/ncomms2409.

Perry, C. T. and Alvarez-Filip, L. (2019). Changing geo-ecological functions of coral reefs in the Anthropocene. Functional Ecology, 33(6):976-988. doi:10.1111/1365 - 2435.13247.

Perry, C. T. and Hepburn, L. (2008). Syn-depositional alteration of coral reef framework through bioerosion, encrustation and cementation: taphonomic signatures of reef accretion and reef depositional events. Earth-Science Reviews, 86(1-4):106-144. doi:10.1016/ j.earscirev.2007.08.006.

Perry, C. T., Murphy, G. N., Kench, P. S., Smithers, S. G., Edinger, E. N., Steneck, R. S., and Mumby, P. J. (2013). Caribbean-wide decline in carbonate production threatens coral reef growth. Nature communications, 4(1):1-7. doi:10.1038/ncomms 2409 .

Purkis, S. J. and Kohler, K. E. (2008). The role of topography in promoting fractal patchiness in a carbonate shelf landscape. Coral Reefs, 27(4):977. doi:10.1007/s00338-008-0404-5.

R Core Team (2013). R: A Language and Environment for Statistical Computing. R Foundation for Statistical Computing, Vienna, Austria.

Rasser, M. and Riegl, B. (2002). Holocene coral reef rubble and its binding agents. Coral Reefs, 21(1):57-72. doi:10.1007/s00338-001-0206-5.

Rioja-Nieto, R. and Álvarez-Filip, L. (2019). Coral reef systems of the Mexican Caribbean: Status, recent trends and conservation. Marine pollution bulletin, 140:616-625. doi:10.1016/j.marpolbul.2018.07.005.

Rodríguez-Martínez, R. E., Jordan-Garza, A. G., Maldonado, M. A., and Blanchon, P. (2011). Controls on coral-ground development along the Northern Mesoamerican Reef Tract. PloS one, 6(12). doi:10.1371/ journal.pone.0028461.

Schutte, V. G., Selig, E. R., and Bruno, J. F. (2010). Regional spatio-temporal trends in Caribbean coral reef benthic communities. Marine Ecology Progress Series, 402:115-122. doi:10.3354/meps08438.

Torgerson, W. S. (1958). Theory and methods of scaling. Wiley. doi:10.2307/2333553.

Toscano, M. A. and Macintyre, I. G. (2006). Reply to Gischler E, Comment on Toscano and Macintyre (2005): corrected western Atlantic sea-level curve for the last 11,000 years based on calibrated $14 \mathrm{C}$ dates from Acropora palmata framework and intertidal mangrove peat Coral Reefs 22: 257270 (2003), and their response in Coral Reefs 24: 187-190 (2005). Coral Reefs, 25(2):281-286. doi: $10.1007 / s 00338-006-0102-0$.

Toth, L. T., Stathakopoulos, A., Kuffner, I. B., Ruzicka, R. R., Colella, M. A., and Shinn, E. A. (2019). The unprecedented loss of Florida's reef-building corals and the emergence of a novel coral-reef assemblage. Ecology, 100(9):e02781. doi:10.1002/bes2.1615.

Vallès, H., Oxenford, H. A., and Henderson, A. (2019). Switching between standard coral reef benthic monitoring protocols is complicated: proof of concept. PeerJ, 7:e8167. doi:10.7717/peerj.8167.

Zvuloni, A., Artzy-Randrup, Y., Stone, L., van Woesik, R., and Loya, Y. (2008). Ecological size-frequency distributions: how to prevent and correct biases in spatial sampling. Limnology and Oceanography: Methods, 6(3):144-153. doi:10.4319/lom.2008.6.144. 